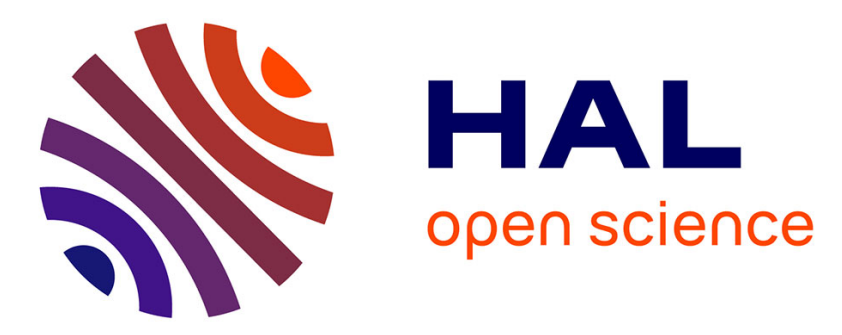

\title{
Numerical modelling for earthquake engineering: the case of lightly RC structural walls
}

J. Mazars, A. Colombo, Panagiotis Kotronis, N. Ile, G. Casaux, Frédéric

Ragueneau, M. Fischinger, D. Marusic

\section{- To cite this version:}

J. Mazars, A. Colombo, Panagiotis Kotronis, N. Ile, G. Casaux, et al.. Numerical modelling for earthquake engineering: the case of lightly RC structural walls. , Computational modelling of Concrete structures, Mar 2003, St. Johann im Pongau, Austria. pp.869-880, 10.1002/nag.363 . hal-01008550

\section{HAL Id: hal-01008550 \\ https://hal.science/hal-01008550}

Submitted on 7 Jan 2020

HAL is a multi-disciplinary open access archive for the deposit and dissemination of scientific research documents, whether they are published or not. The documents may come from teaching and research institutions in France or abroad, or from public or private research centers.
L'archive ouverte pluridisciplinaire HAL, est destinée au dépôt et à la diffusion de documents scientifiques de niveau recherche, publiés ou non, émanant des établissements d'enseignement et de recherche français ou étrangers, des laboratoires publics ou privés. 


\title{
Numerical modelling for earthquake engineering: the case of lightly RC structural walls
}

\author{
J. Mazars, A. Colombo \& P. Kotronis \\ Laboratoire Sols, Solides, Structures INPG and RNVO network, Grenoble, France \\ N. Ile \\ INSA Lyon, France
}

G. Casaux \& F. Ragueneau

LMT Cachan, France

M. Fischinger \& D. Marusic

Institute of Structural and Earthquake Engineering, University of Ljubljana, Slovenia

\begin{abstract}
Different type of analytical models exist to describe the non-linear behaviour of reinforced concrete structures. Based on the level of discretisation, they are often classified as refined or simplified ones. The reliability and the efficacy of the different classes of models in describing the global and the local behaviour of lightly RC structural walls subjected to seismic loadings are investigated in this paper. The results of an experimental campaign carried out as a part of the CAMUS 2000 research program are used as a reference.
\end{abstract}

\section{INTRODUCTION}

Reinforced concrete bearing walls with limited reinforcement ratios are commonly used in France and other European countries for building structures. Research up to date on this type of walls (e.g. CASSBA, CAMUS programs) has shown that such kind of constructions exhibited good behaviour under seismic loading, although their ductility might be limited due to the light reinforcement and the large wall regions having practically no reinforcement (Mazars 1998). Results of these research programs highlighted some unconventional mechanisms of earthquake resistance, such as the rigid block-type rotations of the walls (or part of) that take place at the interface between the foundation and the soil or at the level of cold construction joints. Consequences of this behaviour mechanism are the high frequency vertical vibrations excited in the walls due to the opening and closing of wide horizontal cracks, the conversion of part of the seismic energy into potential energy, etc.

On the other hand, in case of real structures such walls are likely to be loaded in the out of plane direction as well. Due to the out of plane loading, additional fluctuation of the axial force may arise and more damage is to be expected since cracks may not completely close at load reversal. It is clear that all these effects are hard to quantify within the framework of conventional elastic seismic analysis. Reliable numerical tools become more than necessary to assist engineers in the design phase.

Many analytical models have been proposed up to date for the non-linear analysis of reinforced concrete structures. They range from very refined and complex local ones to simplified global models. The level of refinement is usually correlated to the dimension of the problem. Refined analytical models are typically used in predicting the response of small structures or substructures, whereas simplified global models are useful for the dynamic response analysis of large structures.

In this paper the performance of both refined (a 3D finite element thin shell modellisation based on the use of shells, bars and solid elements) and simplified models (a fibre model and a beam model with multiple integration points) is evaluated by comparing the numerical with the experimental results of a five-storey lightly reinforced concrete wall submitted to dynamic loading. This experimental campaign was performed within the CAMUS 2000 research program presented hereafter.

\subsection{The CAMUS 2000 research program}

The 3-years combined experimental and numerical research program CAMUS 2000 was launched in 1998 with the aim of evaluating the effects of torsion and the behaviour of lightly reinforced walls subjected to bi-directional motions.

As a part of the program two scaled (1/3) models representative of a five-storeys reinforced concrete building (Fig.1) have been tested on the major Azalee shaking table of Commissariat à l'Energie Atomique (CEA) in the Saclay Nuclear Centre. The first structure (CAMUS 2000-1) has been subjected to a horizontal bi-directional excitation. A set of accelerograms was applied at increasing amplitude (effective acceleration equal to $0.15 \mathrm{~g}, 0.22 \mathrm{~g}, 0.25 \mathrm{~g}$, $0.40 \mathrm{~g}, 0.55 \mathrm{~g}$ and $0.65 \mathrm{~g}$ ). Structural stiffness was 
provided by two identical shear walls in one direction and a steel bracing system in the orthogonal direction. For the second test (CAMUS 2000-2), an in plane excitation was applied. A torsional response was caused by the asymmetry in the horizontal dimensions of the two walls.

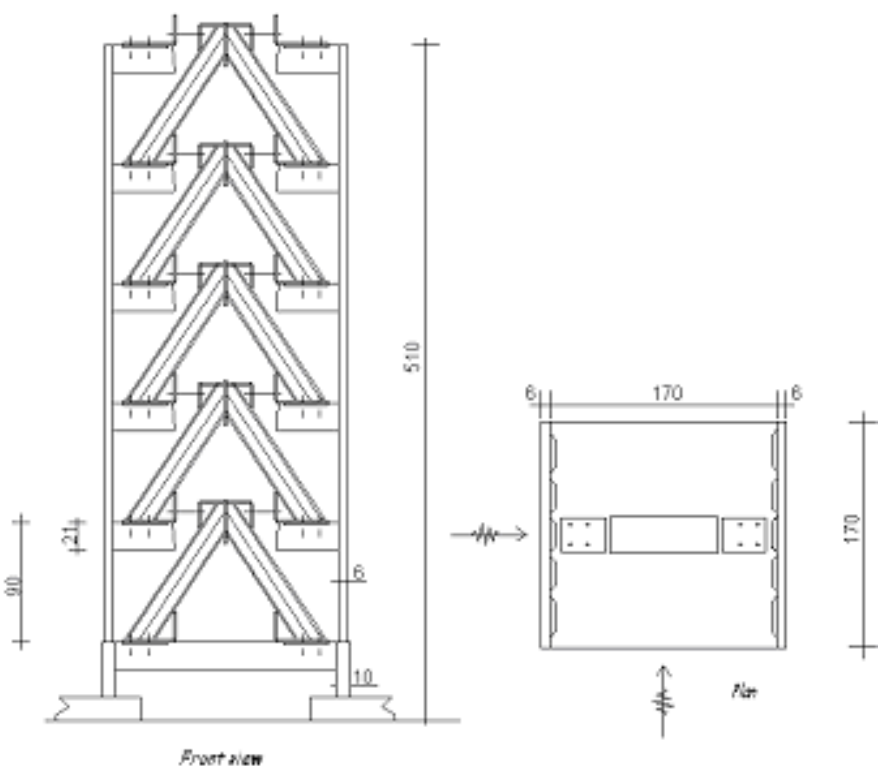

Figure 1. Layout of the specimen.

\section{3D THIN SHELL MODELLING}

\subsection{Material modelling}

In order to achieve a good compromise between simplicity and accuracy a biaxial concrete model that provides acceptable representation of the cyclic inelastic behaviour of reinforced concrete under cyclic loading was used. This model (Merabet \& Reynouard 1999) adopts the concept of a smeared crack approach with a possible double cracking only at $90^{\circ}$. It is based upon the plasticity theory for uncracked concrete with isotropic hardening and associated flow rule. Two distinct criteria describe the failure surface: Nadai in compression and bicompression and Rankine in tension. Hardening is isotropic and an associated flow rule is used. When the ultimate surface is reached in tension, a crack is created perpendicularly to the principal direction of maximum tensile stress, and its orientation is considered as fixed subsequently. Each direction is then processed independently by a cyclic uniaxial law, and the stress tensor in the local co-ordinate system defined by the direction of the cracks is completed by the shear stress, elastically calculated with a reduced shear modulus $\mu G$, (with $0<\mu<1$, and $\mu$ being a function of the crack opening strain) to account for the effect of interface shear transfer:

$$
\begin{aligned}
& \mu=0.4 \quad \text { if } \varepsilon_{\mathrm{cr}^{-}} \varepsilon_{\mathrm{res}^{-}} \varepsilon_{\mathrm{tm}}=2 \varepsilon_{\mathrm{tm}} \\
& \mu=0 \quad \text { if } \varepsilon_{\mathrm{cr}^{-}} \varepsilon_{\mathrm{res}^{-}} \varepsilon_{\mathrm{tm}}=2 \varepsilon_{\mathrm{tm}}
\end{aligned}
$$

$\mu=0$ and $\sigma_{12}=0$ if $\varepsilon_{\mathrm{cr}^{-}} \varepsilon_{\mathrm{res}}-\varepsilon_{\mathrm{tm}}=4 \varepsilon_{\mathrm{tm}}$

(3) 
in which: $\varepsilon_{\mathrm{cr}}$ is the total strain, $\varepsilon_{\text {res }}$ the residual strain after unloading in compression, $\varepsilon_{\text {tm }}$ the crack opening strain and $\sigma_{12}$ the shear stress.

The behaviour of a point initially under tension, which completely cracks prior to undergoing a reverse loading in compression, is illustrated in Figure 2. Similar laws describe the case of an initial compressed point or that of a point which has not totally cracked under a reverse loading. The model has been described in detail and verified elsewhere (Ile 2000), (Ile \& Reynouard 2000), (Fleury 1996).

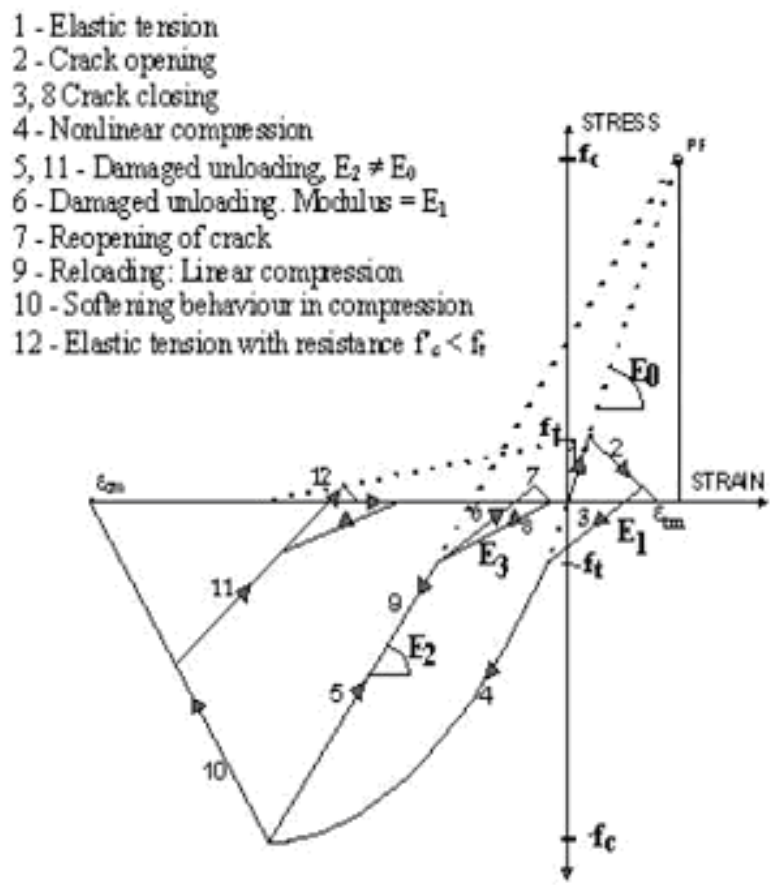

Figure 2. Uniaxial model: point initially in tension.

For steel, a cyclic model that can take into account the Bauschinger effect and buckling of reinforcing bars has been adopted. The monotonic branch is characterised by an initial linear branch followed by a plateau and hardening up to failure. The cyclic behaviour is described by the formulation proposed by Giuffré and Pinto and implemented by Menegoto \& Pinto (1973). The steel model is presented in Figure 3.

The evaluation of steel parameters was quite simple, the measured elasticity modulus $-200000 \mathrm{MPa}$, yield stress - $664 \mathrm{MPa}$, failure stress - $733 \mathrm{MPa}$ and strain at failure $-2.2 \%$, being directly used. For concrete, the material properties were generally as provided by the CAMUS 2000-1 experimental data (Fouré 2001) and design codes: $23000 \mathrm{MPa}$ for the initial elastic modulus, $34 \mathrm{MPa}$ for the compressive strength and 2.6 MPa for the tensile strength. An initial value of 0.40 for the post-cracking parameter $\mu$ was assumed in the analysis.

\subsection{Model description}

The numerical analyses have been performed using the general-purpose finite element program
CASTEM 2000 developed at CEA-Saclay (Millard 1993). To predict the inelastic seismic response of the tested structures with sufficient accuracy, special care has been taken to create detailed models of the specimens, taking into account the necessary geometric characteristics, construction details and boundary conditions. An example of the 3-D finite element mesh used in the analyses is reported in Figure 4.

Figure 3. Numerical model for steel under cyclic loading.

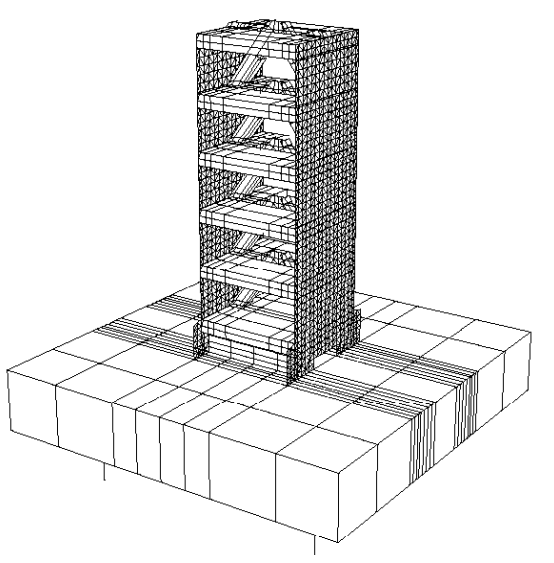

Figure 4. 3-D finite element mesh of the CAMUS 2001 specimen including the shaking table.

Due to the direction of the applied loading, in plane as well as out of plane behaviour of the walls needs to be analysed. Therefore, layered thin shell discrete Kirchoff triangles (DKT) are used to repre-

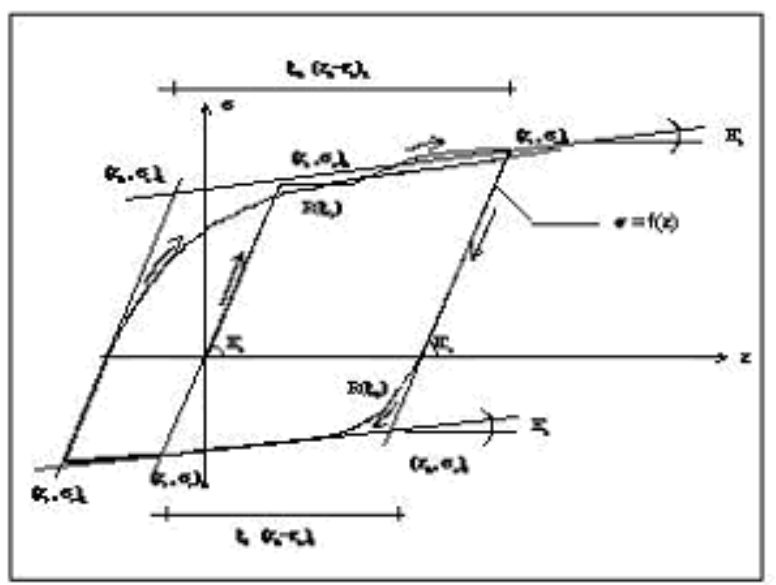

a) cyclic behaviour without buckling

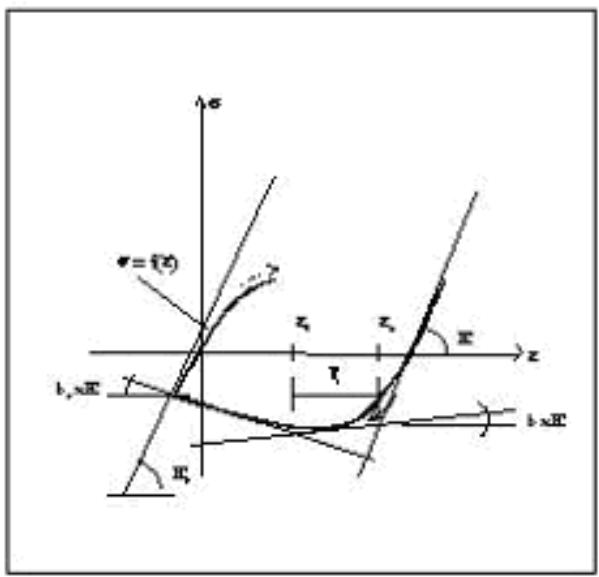

b) cyclic behaviour with buckling 
sent the two walls. The slabs, as well as the shaking table are modelled with solid eight-node brick elements, while four-node shell elements are used to model the steel I-shaped bracing system. A discrete modelling is adopted to represent the horizontal and vertical reinforcement through the use of two-node truss-bar elements. The structure is assumed fully restrained at all nodes along the base of the shear wall, but the shaking-table was considered as a rigid block fixed to 4 vertical restraining rods, the axial stiffness of each rod being estimated equal to 215 $\mathrm{MN} / \mathrm{m}$. Perfect bond was assumed to exist between concrete and reinforcement. The possibility of nonlinear material behaviour was specified for all the wall concrete elements and reinforcing bar-elements, while the behaviour of the slabs, bracing system and shaking-table was considered as elastic.

Assuming a 2\% critical damping factor (close to the measured value) for the first and second vibration mode, the damping parameters and were calculated and used subsequently to form the Rayleigh damping matrix $[\mathrm{C}]=\alpha[\mathrm{M}]+\beta[\mathrm{K}], \mathrm{M}$ and $\mathrm{K}$ being the mass and stiffness matrix. Despite the fact that a modal characterisation is theoretically correct only for linear elastic systems, the damping matrix [C] obtained in this way is assumed to remain constant throughout the loading cycle. Since with increasing damage, modal frequencies decrease due to cracking and reinforcement yielding, this assumption may lead to unrealistic over damping on lower modes. When several sequential input motions are considered in a seismic analysis, the best choice would probably be to reduce the Rayleigh damping matrix with increasing applied motion. The drawback of this approach relies on the difficulty of selecting a suitable value for the damping matrix. Notwithstanding the complexity of the problem, it seems however, that the viscous over damping effect may be partially compensated by the fact that the present non-linear model cannot take properly into account all sources of hysteretic damping: unilateral cracking, shear slip between the lips of the crack, bond-slip between steel and concrete, etc. In any case, since one of the aims of the present study was to test the capabilities of the existing cyclic model, all modelling decisions (including the choice of a constant damping matrix) were made before all calculations were executed and no tuning of the analysis was done in an attempt to obtain a better fit to the experimental results. To solve the non-linear equilibrium equations, a modified Newton-Raphson iteration solution scheme was used.

\subsection{Main results}

In order to take into account the effect of accumulation of damage a series of 4 non-linear time-history dynamic analyses were sequentially performed. The following PGA levels of the uncorrelated input signals applied during the test (in direction $\mathrm{x}$ and $\mathrm{y}$ ) were considered in the numerical analyses: $0.22 \mathrm{~g}$, $0.40 \mathrm{~g}, 0.55 \mathrm{~g}$ and $0.65 \mathrm{~g}$. A large number of results, which are still under investigation, have been produced. For the sake of brevity, only the main results related to the last input motion $(\mathrm{PGA}=0.65 \mathrm{~g}$ ), which caused failure of the specimen are presented and discussed here.

The time history of the calculated roof displacement is compared in Figure 5 with the corresponding measured displacement. It can be observed that the maximum in-plane horizontal displacements are reasonably predicted (here given at the top of the left wall for both $0.55 \mathrm{~g}$ and $0.65 \mathrm{~g}$ ), while the model generally underestimates the out of plane displacement.
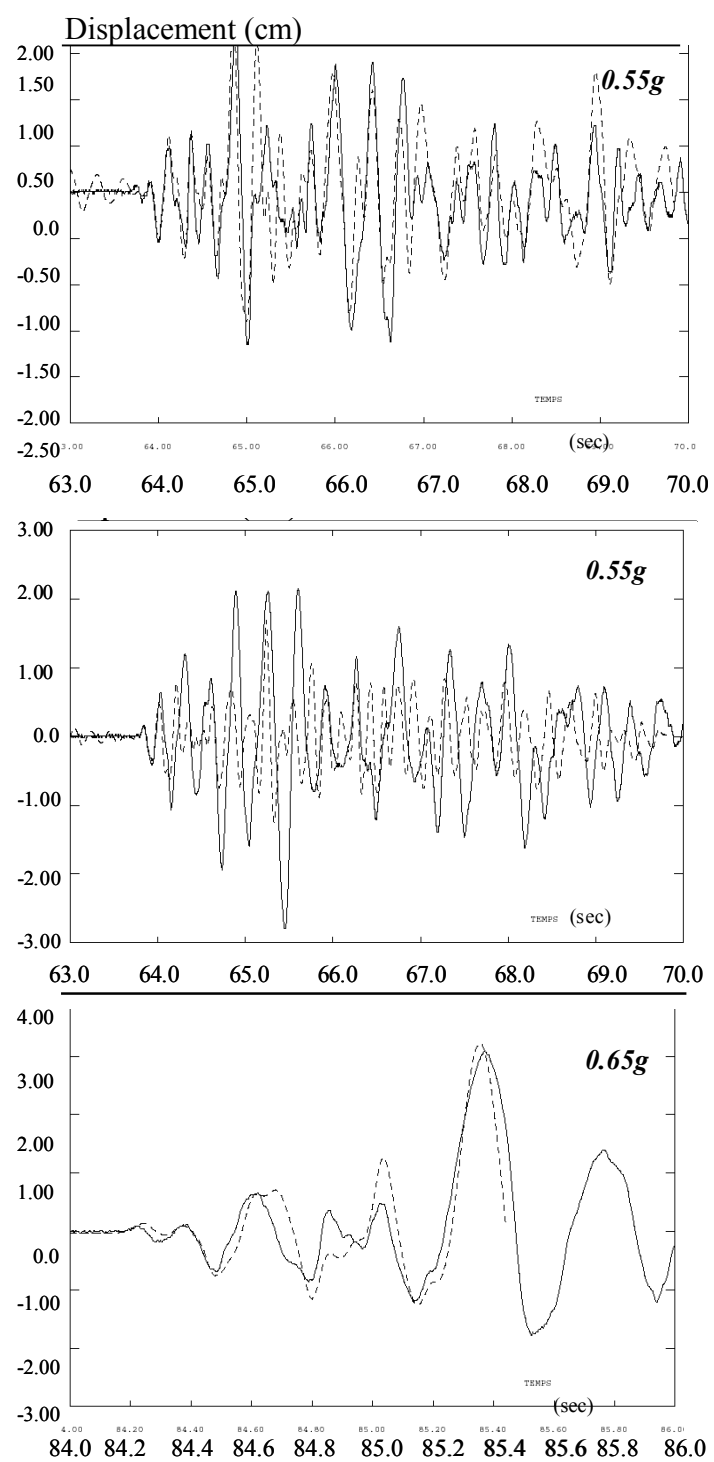

Figure 5. Comparison between calculated and measured horizontal top displacements: A) in plane displacement $(0.55 \mathrm{~g})-$ left wall; B) out-of-plane displacement $(0.55 \mathrm{~g})$. C) in plane displacement $(0.65 \mathrm{~g})$-left wall; 
Actually, during this last test, the failure of the connection of the bracing system with the slab was also obtained, one branch of the bracing system being completely dislocated from the slab. This was probably due to a higher out of plane shear force than anticipated in design. Since the behaviour of this connection was considered as elastic in the analysis, the observed discrepancies between experimental results and analysis seem normal.

For the last test on CAMUS 2000-1, a large variation of the axial force has been observed, its amplitude, at the base of the first story, being comparable with the static axial force, which is about 165 $\mathrm{KN}$ for one wall. One part of the axial force variation, denoted here as "dynamic axial force", comes from the extension mode caused by the in plane bending of the walls: at maximum horizontal deflection, the neutral axis is at its maximum distance from the centre of the wall cross-section, the raising of masses is maximum and the dynamic variation of the axial force is a tensile force; the frequency of this vertical motion is two times that of the horizontal movement; then, at cracks closure, when concrete recovers its stiffness, compression forces strongly increase and these shocks excite the vertical vibration mode of the system (shaking table + specimen), which is about $20 \mathrm{~Hz}$. This variation was also observed during the previous CAMUS in plane seismic tests (Bisch \& Coin 1998).

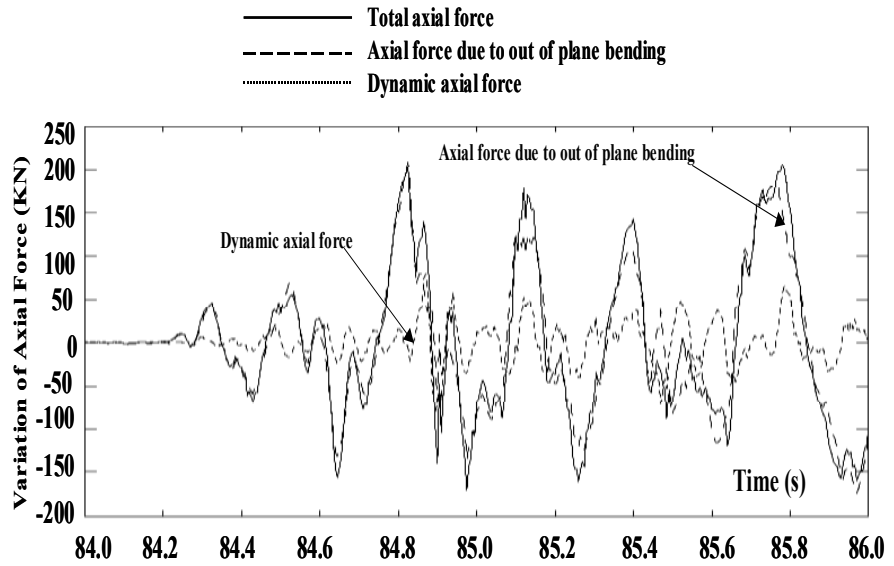

Figure 6. Variation of the axial force at the base of the first story $(\mathrm{PGA}=0.65 \mathrm{~g})$ for one wall: $\mathrm{A}$ ) experimental and $\mathrm{B}$ ) numerical results.
The other part of the axial force variation comes from the out of plane bending, which induces a complementary compressive axial force in one wall and a tensile axial force in the other. The total axial force variation in each wall is then obtained by summing the corresponding values of the dynamic axial force and of the axial force due to the out of plane bending. The different components of the experimental axial force variation in the left wall, as obtained from the last test $(\mathrm{PGA}=0.65 \mathrm{~g})$ are shown in Figure 6.

When comparing these results it can be noted that the total variation of the axial force is mainly due to the out of plane bending component which is several times larger than the dynamic axial force. This is due to the fact that the specimen was subjected perpendicular to the walls plane (y direction) to a PGA level as high as that applied in the direction of the walls plane (x-direction) and to the fact that the frequency of the out of plane vibration mode was close to that corresponding to the in plane vibration mode (around $6 \mathrm{~Hz}$ ).

For comparative purposes the variation of the total axial force in the left wall and at the base of the first story as deduced from analysis is presented in Figure 6B. As the analysis was stopped after rupture of one reinforcing bar, the analysis time scale is not as large as that corresponding to the previous figure. By comparing Figure 6A and 6B it can be noted that the maximum variation of the dynamic axial force is comparable with the measured values.

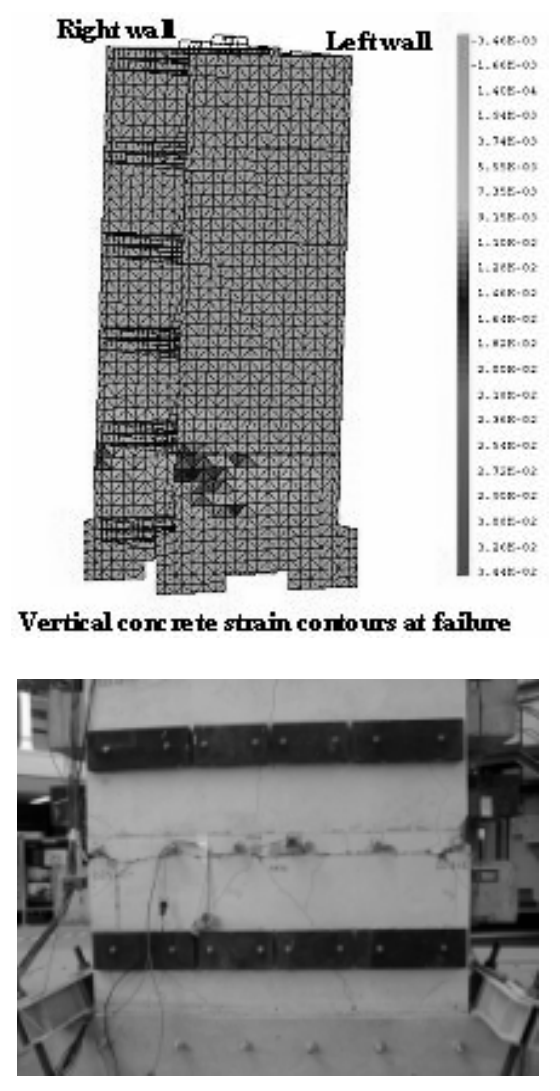

Figure 7. Comparison between test and analysis at failure: A) numerical vertical concrete strain contour at failure, B) crack pattern at the end of the test. 
Local results as obtained from the dynamic analysis are seen in Figure 7. This figure depicts the damage distribution obtained just after one of the steel bars of the left wall has broken in tension.

It is to be noted that cracks are almost horizontally distributed in the two walls, but the crack opening is larger for the wall, which is in tension. The analysis also showed that damage is almost entirely concentrated just under the $2^{\text {nd }}$ floor level, level where the main cracks develop. Actually, inspection after the test showed that the steel bars were broken bellow the second floor level and a large horizontal crack develops at the same level.

\section{FIBRE MODEL}

Non-linear dynamic analysis of civil engineering structures requires large scale calculations, implying delicate solving techniques. The necessity to perform parametrical studies led us to adopt special solutions in order to reduce the computational cost. The response of a structure submitted to severe loadings, depends on a strong interaction between "material" (local non-linearities), "structural"(geometry, mass distribution, joints) and "environment" (interaction of the structure with its support) effects. For concrete structures, the local material behaviours are the major sources of non-linearities. The wish to keep good prediction ability for the model guided us to use refined constitutive equations, taking into account the main physical phenomena (damage, inelasticity, crack-reclosure, ...). At a structural level, the choice of a "simplified approach" has been made by applying simplifying assumptions compromising as little as possible the quality of results.

The choice of using a multifiber F.E. configuration combines the advantage of using beam type finite elements with the simplicity of uniaxial behaviour. Each finite element is a beam discredited into several fibres (see Figure 8). The F.E. code used is again CASTEM 2000.
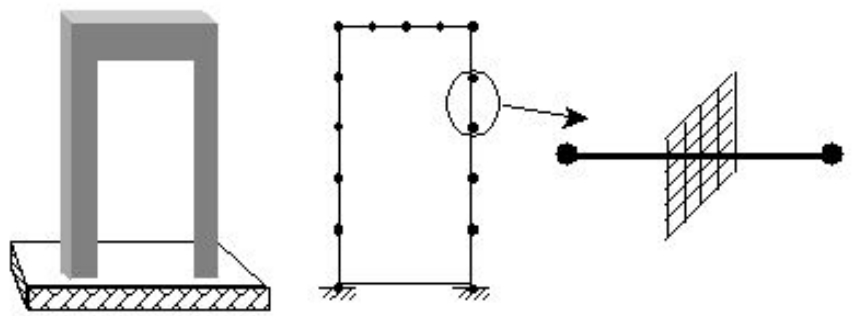

Figure 8. Multifiber discretisation principle.

A first series of calculations (modal analysis) have been performed in order to insure that the main phenomena of the problem have been well represented. Figure 9 gives a comparison of the multifiber approach with both the experimental and the ful- ly $3 \mathrm{D}$ calculation results for the first three natural modes.

Figure 9. Natural modes : on the left fibre model on the right 3D model. From the top to the base :

In plane : fibre : $6.00 \mathrm{hz}, 3 \mathrm{D}: 6.14 \mathrm{~Hz}, \exp : 6.00 \mathrm{~Hz}$

Out of plane : fibre : $5.5 \mathrm{~Hz}, 3 \mathrm{D}: 6.07 \mathrm{~Hz}$, exp.: $5.45 \mathrm{~Hz}$

Torsion : fibre : $10.5 \mathrm{~Hz}, 3 \mathrm{D}: 10.73$, exp. : ?

As it has been already discussed, the shaking table - due to its softness - must also be included to the mesh (using 3D elements or orthogonal beams for the two models respectively) to insure the good correlation of the calculations. The results obtained with the fiber model are as good as those obtained with the 3D FEM model, with a much less significant cost.

\subsection{Material modelling}

Material modelling for reinforced concrete structures submitted to dynamic loading has to take into account the decrease of stiffness as well as plasticity of the reinforcements till failure.

In describing the non-linear behaviour of reinforcement rebars, a classical plasticity model taking into account a non-linear cinematic hardening (Armstrong et al., 1966) has been implemented. Response under uniaxial cyclic loading is presented in Figure 10.

Seismic loading, which includes cyclic aspects, produces micro cracking in concrete. Some major phenomena have to be taken into account:

- decrease in material stiffness as the micro cracks open,

- stiffness recovery as crack closure occurs, inelastic strains concomitant to damage.

Figure10. Uniaxial stress-strain relations for concrete and
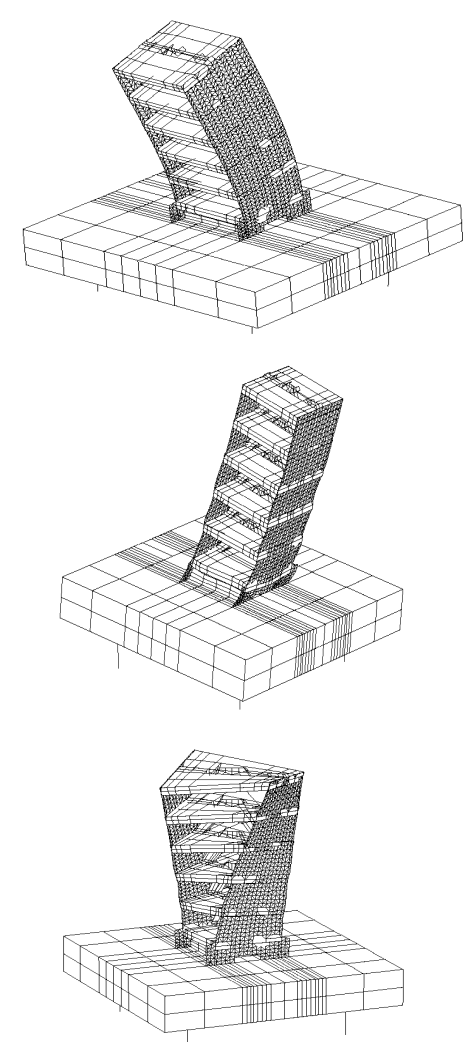


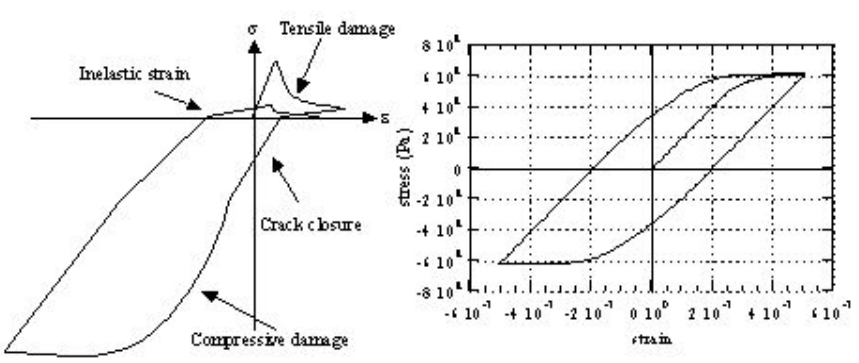

To account for such a behaviour we adopt a continuum damage model (La Borderie 1991), which incorporates two scalar damage variables, one for damage due to tension $\mathrm{D}_{1}$, the other for damage due to compression $\mathrm{D}_{2}$ and which includes a recovery stiffness procedure and the description of isotropic inelastic strain. Constitutive equations are:

total strain: $\boldsymbol{\varepsilon}=\boldsymbol{\varepsilon}^{e}+\boldsymbol{\varepsilon}^{\text {in }}$

$$
\begin{aligned}
& \boldsymbol{\varepsilon}^{e}=\frac{\langle\boldsymbol{\sigma}\rangle_{+}}{E\left(1-D_{1}\right)}+\frac{\langle\boldsymbol{\sigma}\rangle_{-}}{E\left(1-D_{1}\right)}+\frac{v}{E}(\boldsymbol{\sigma}-\operatorname{Tr}(\boldsymbol{\sigma}) \boldsymbol{1}) \\
& \boldsymbol{\varepsilon}^{i n}=\frac{\beta_{1} D_{1}}{E\left(1-D_{1}\right)} \frac{\partial f(\boldsymbol{\sigma})}{\partial \boldsymbol{\sigma}}+\frac{\beta_{2} D_{2}}{E\left(1-D_{2}\right)} \boldsymbol{l}
\end{aligned}
$$

with $\varepsilon^{e}$ elastic strains and $\varepsilon^{i n}$ inelastic strains. 1 denotes the unit tensor and $\operatorname{Tr}(\sigma)=\sigma_{i i}$

Damage criteria are expressed as: $f_{i}=Y_{i}-Z_{i}$ With $Y_{i}$, associates forces to damage and $Z_{i}$ the hardening variable. The evolution laws for damage take the following form:

$$
D_{i}=1-\frac{1}{1+\left[A_{i}\left(Y_{i}-Y_{0 i}\right)\right]^{B_{i}}}
$$

where $f(\sigma)$ and $\sigma_{f}$ are the crack closure function and the crack closure stress respectively. $<.>+$ denotes the positive part of a tensor. $E$ is the initial Young's modulus and $v$ the Poisson ratio. $\mathrm{D}_{1}$ and $\mathrm{D}_{2}$ are respectively the damage variables for traction and compression. $\beta_{1}$ and $\beta_{2}$ are material constants. Figure 10 gives the stress-strain response of that model for a uniaxial traction-compression-traction loading.

\subsection{Model description}

The finite element mesh has already been presented in Figure 9. The additional masses and the weight load of each floor are concentrated at each story. The stiffness of the springs below the shaking table is identified so as to feet the first eigenmodes measured on the virgin structure before the seismic loadings. Despite the lack of physical meaning, damping is generally introduced in the analysis through viscous forces generated by the means of a damping matrix. This is the classical Viscous Rayleigh damping matrix, derived from the general expression pro- posed by Caughey (1960). The two parameters allow calibrating the matrix by imposing the value of the damping ratio for two eigenmodes of the virgin structure. The Rayleigh damping coefficients have been adjusted to ensure a value of $1 \%$ on the first mode and $2 \%$ on the second mode. Great attention has been focused to keep these damping values as stable as possible throughout the analysis. This remark may become important for concrete structures where cracking induces loss in stiffness and by that way a shift of the fundamental frequency. Therefore the damping of the first eigen mode has been chosen so as to remain around the minimum constant range of the Rayleigh diagram.

\subsection{Main results}

Results are presented in terms of horizontal top displacements in the plane (X direction) of the walls (Fig. 11) and global flexural moment in the Y direction (Fig. 12) for the signal corresponding to $0.55 \mathrm{~g}$.

Figure 11. In plane top horizontal displacement: $0.55 \mathrm{~g}$ of maximum acceleration.

Figure 12 . Out plane bending moment: $0.55 \mathrm{~g}$ of maximum ac-

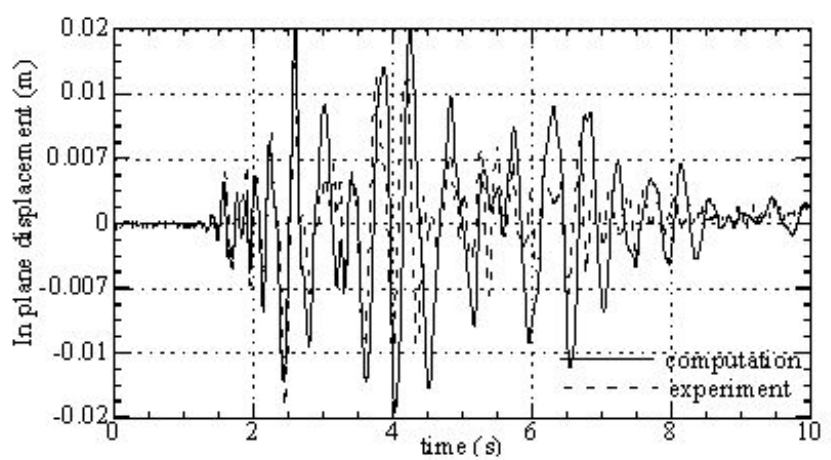

celeration.

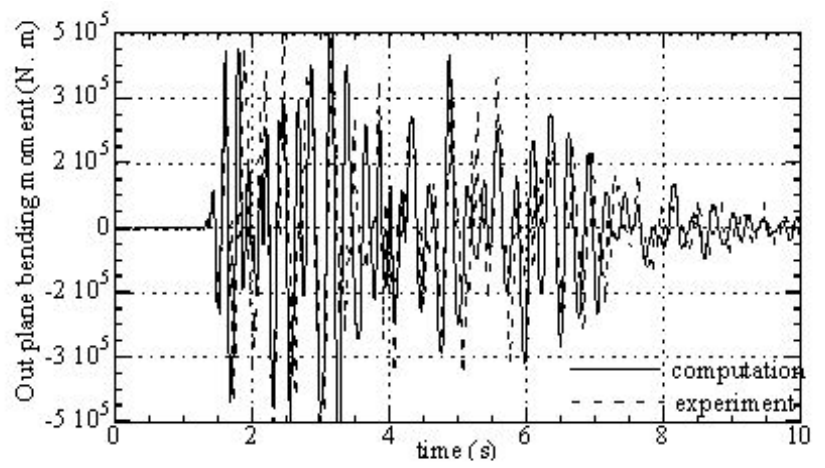

These results have been obtained without calibration with the experimental results. Work is in progress on the effects of damping and improvements of the modelling are carried out to account for torsion and 3D material behaviours using an enhanced beam formulation. 


\section{BEAM MODEL}

The realistic dynamic description and modelling of material failure is one of the actual problems in structural mechanics. Analyses of failure processes require the use of complex FE discretisation and advanced constitutive models. For modelling of concrete it is necessary to capture several important phenomena such as development of anisotropy, damage and ductility (possibly softening). This implies the description of the concrete behaviour with refined constitutive models. Such complex analyses demand for large scale computing, which must be feasible from the view of both time and available resources. In this light the use of simplified modellisations coupled with explicit procedures became very popular for solving time dependent problems. Together with the limited number of numerical elements used in simplified approaches, the utilization of explicit procedures contributes to a general reduction of the time requested by the calculation, since they require no iterations and no tangent stiffness matrix. Even though they are in general conditionally stable, their stability is automatically assured by the small time increments required by the solution of dynamic problems.

To verify the efficiency of both simplified approaches and explicit methods in describing the seismic behaviour of reinforced concrete wall structures a three-dimensional finite element model of the building was realized by using only beam elements with multiple integration points. This model differs from the one presented in the previous paragraph in the fact that structural members are characterised by a homogeneous cross-section. The explicit version of the commercial computer code ABAQUS version 6.1 has been chosen for the analyses.

The main characteristics of the element chosen for the modelling of the spatial behaviour of the structure are listed below.

- The beams used are Timoshenko beams that allow for transverse shear deformation. The transverse shear deformation is treated as if the response were linear elastic, independent of the axial and bending responses, even for non-linear material behaviour.

- A lumped mass formulation is used.

- The cross-section of each beam is integrated numerically to obtain the force-moment/straincurvature relations for the section, which allows complete generality in material response, since each point of a section is considered independently by the constitutive routines.

\subsection{Material modelling}

The elastic-plastic model implemented in ABAQUS has been used to describe the behaviour of steel members. The cyclic behaviour of concrete has been represented by using the PRM model (Mazars 1986, Pontiroli 1995, Rouquand \& Mazars 2001). The analysis has been carried out with ABAQUS and the explicit version of the PRM model running in parallel.

The PRM model is based on constitutive laws able to account for the effects of stiffness deterioration, recovery of stiffness due to crack closure, effects of damage and strain rate. The main particularities of the model are given for a uniaxial loading as follows:

- Partition of strain and stress tensors:

$\varepsilon=\varepsilon_{\mathrm{d}}+\varepsilon_{\mathrm{ft}} \quad \& \quad \sigma=\sigma_{\mathrm{d}}+\sigma_{\mathrm{ft}}$

- Combination of two modes of damage:

$\mathrm{D}=\alpha_{\mathrm{t}} \mathrm{D}_{\mathrm{t}}+\left(1-\alpha_{\mathrm{t}}\right) \mathrm{D}_{\mathrm{c}}$

$\alpha_{t}$ evolved in between 0 and 1 and the actual values depends on $\left(\varepsilon-\varepsilon_{\mathrm{ft}}\right)$

$D_{i}=$ fct $\left(\widetilde{\varepsilon}, \varepsilon_{d 0}, A_{i}, B_{i}\right)$ with $\mathrm{i}=\mathrm{t}, \mathrm{c}$

(9)

$\mathrm{D}_{\mathrm{t}}$ damage in tension, $\mathrm{D}_{\mathrm{c}}$ damage in compression. $\widetilde{\varepsilon}$ is the equivalent deformation, (function of the local principal positive strain $\widetilde{\varepsilon}=\sqrt{\left\langle\varepsilon_{i}\right\rangle_{+}^{2}}$, Mazars 1986) which pilots the damage evolution after the initial threshold $\varepsilon_{\mathrm{d} 0}, \mathrm{~A}_{\mathrm{i}}, \mathrm{Bi}$ are material parameters.

- Constitutive equations:

$\left(\sigma-\sigma_{\mathrm{ft}}\right)=\Lambda_{0} \cdot(1-\mathrm{D}) \cdot\left(\varepsilon-\varepsilon_{\mathrm{ft}}\right)$

In order to describe dissipation due to hysteretic loops (Fig. 13) a hysteretic stress term is added:

$\sigma_{\text {hyst }}=\left(\beta_{1}+\beta_{2} \mathrm{D}\right) \mathrm{E}(1-\mathrm{D})\left(\varepsilon-\varepsilon_{\mathrm{ft}}\right) \mathrm{f}\left(\varepsilon-\varepsilon_{\mathrm{ft}}\right)$

$\beta_{1}$ and $\beta_{2}$ are "Rayleigh" parameters and $\mathrm{f}$ is a function used to calibrate the evolution with the strain.

The problem becomes more simple if described in a new repair $\mathrm{R}_{\mathrm{ft}}\left(\sigma_{\mathrm{ft}}, \varepsilon_{\mathrm{ft}}\right)$ as shown in Figure 13. The general 3D formulation of the model linking strain and stress tensors (in bold) is reported below:

$$
\begin{aligned}
& \left(\sigma-\sigma_{\mathrm{ft}}\right)=\Lambda_{0}(1-\mathrm{D}) \quad\left(\varepsilon \quad-\varepsilon_{\mathrm{ft}}\right) \\
& (12) \\
& =\alpha \mathrm{t}\left(1-\mathrm{D}_{\mathrm{t}}\right)\left[\lambda_{0} \operatorname{trace}\left(\varepsilon-\varepsilon_{\mathrm{ft}}\right) 1+2 \mu_{0}\left(\varepsilon-\varepsilon_{\mathrm{ft}}\right)\right] \\
& +(1-\alpha \mathrm{t})\left(1-\mathrm{D}_{\mathrm{c}}\right)\left[\lambda_{0} \operatorname{trace}\left(\varepsilon-\varepsilon_{\mathrm{ft}}\right) 1+2 \mu_{0}\left(\varepsilon-\varepsilon_{\mathrm{ft}}\right)\right]
\end{aligned}
$$

where $\sigma_{f t}$ and $\varepsilon_{f t}$ are the crack closure stress and strain thresholds used to manage permanent effects; $\Lambda_{0}$ is related to the initial mechanical characteristics.

One of the main advantages of this model is that it includes crack-closure effects, describes permanent strains, hysteretic loops and is expressed in an explicit form, compatible with the use of an explicit algorithm. 


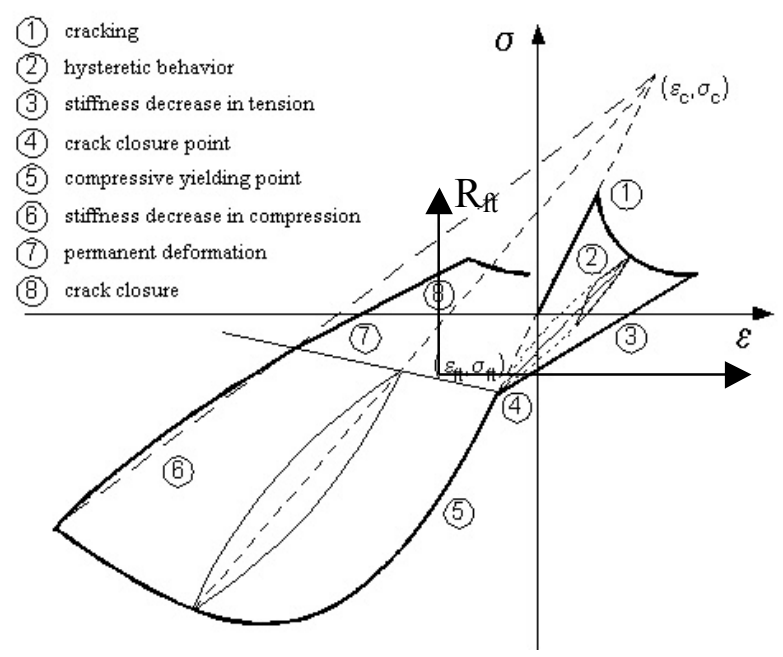

Figure 13. PRM model: stress-strain relationship.

\subsection{Model description}

The same type of element has been used to represer the various structural components but with differer sections.

- Walls. Rectangular section elements were chose to model the concrete of the walls. 25 integratio points characterize each section. The longitudinc. reinforcement is accounted for by means of box section elements. Couples of bars at the same distance from the axis of the structural member were modelled by using the same numerical element the area of the reinforcing bars has been transformed into an equivalent area of the box section. This choice allowed the representation of the walls to be done directly by the geometrical description of their axis. 16 integration points characterize each section. The additional masses placed along the walls have been modelled using concentrated masses.

- Slab. Rectangular and box section elements have been used to mesh the slabs. As for the walls, reinforcing bars have been accounted for through the use of box section. The mass blocks added to the floors to represent the dead load of the structure have been modelled by using fictive box sections: the density of the material has been chosen to represent the real weight of the blocks, whereas the stiffness of the elements has been limited, in order to avoid their influence on the dynamic behaviour of the structure.

- Bracing system. The bracing system has been modelled with I-section elements. The geometry of sections corresponds to the steel section adopted in reality. 13 integration points characterize each section.

- Basement. A network of elements has been used to simulate the stiffness of the basement in the three directions. As for the other structural ele- ments, rectangular sections were adopted for concrete whereas the reinforcement has been modelled using box sections. The basement of the specimen is connected to the table through four circular section beams elements. A preload is applied to these components so as to reproduce the reality.

- Shaking table. A rigid body composed by rectangular section beams has been used to describe the behaviour of the shaking table. Circular beam elements have been chosen to simulate the deformability of the table. The mass of the table has been accounted for by defining an appropriate

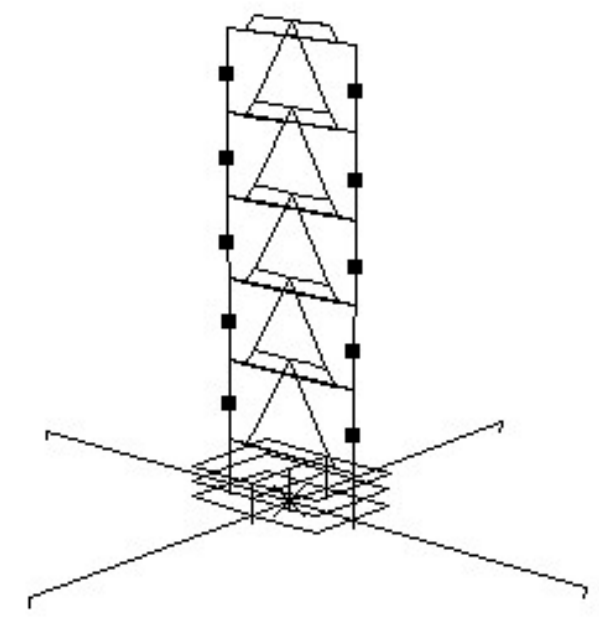
analysis is

Figure 14. Simplified beam model.

\subsection{Main results}

A first verification of the model was carried out by performing a modal analysis. The first two frequencies obtained with the numerical model (5.5 and $6.02 \mathrm{~Hz}$ for the out-of-plane and the in-plane flexure) were similar to the measured ones (5.45 and 6.00 HZ respectively).

Seven seismic signals of increasing amplitude have been applied during the experimental campaign. Among them, only those corresponding to an intensity of $0.15 \mathrm{~g}, 0.4 \mathrm{~g}$ and $0.55 \mathrm{~g}$ have been considered in the numerical study. In spite of the simplified approach adopted in the analysis, numerical and experimental data were in good agreement both at global and at local level. Displacement time histories obtained for $0.55 \mathrm{~g}$ in the direction parallel to that of the walls are shown in Figure 15. The agreement at this stage is good; some differences have been detected from the experimental and the numerical displacements at $0.4 \mathrm{~g}$. The reason for these dissimilarities can be found in the damage that might be suffered by the specimen during the application of the signals not considered in the analysis. The better agreement obtained for the signal of $0.55 \mathrm{~g}$ seems to verify this assumption. For the same intensity, the 
fair agreement between experimental and numerical axial load and moment time histories can also be observed in Figure 16 that represents an additional proof of the reliability of the model.

A complex state of stress inside the walls caused by the combination of bi-directional flexure and

In-plane displacement - right wall - ag $=0.40$

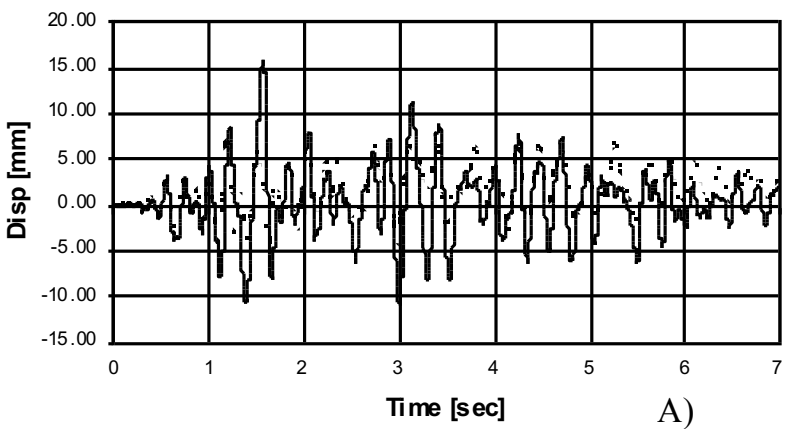

In-plane displace ment - right $\mathbf{w}$ all $-\mathbf{a g}=\mathbf{0 . 5 5}$

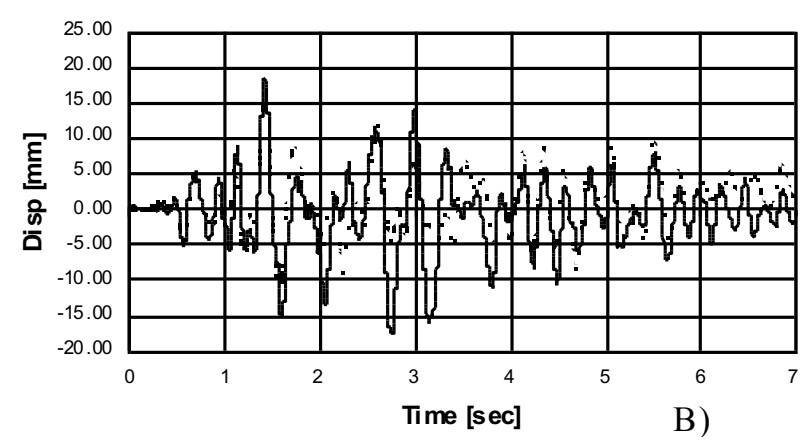

shear similar to that observed during the tests was also highlighted by the numerical analyses.

Figure 15. Comparison between calculated (dotted line) and

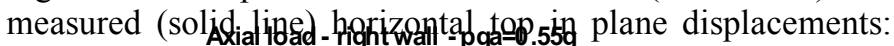
A) signal of $0.4 \mathrm{~g} ; \mathrm{B})$ signal of $0.55 \mathrm{~g}$.

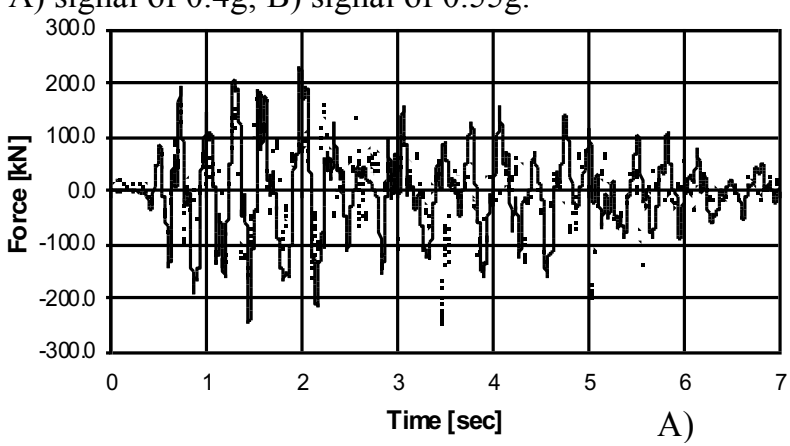

Global Moment - pga $=0.55 \mathrm{~g}$

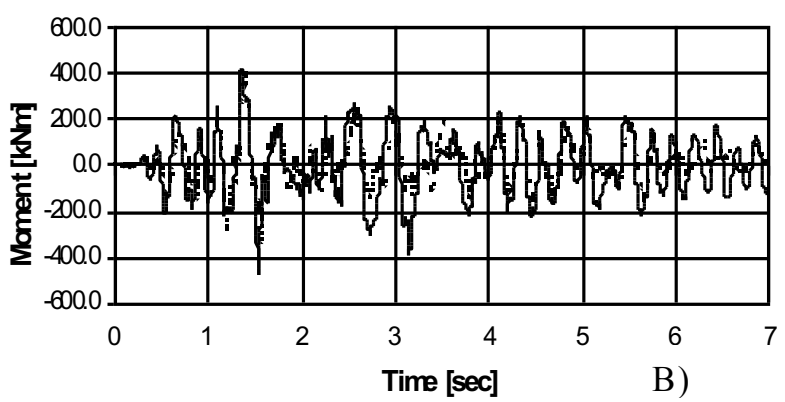

Figure 16. Comparison between calculated (dotted line) and measured (solid line) axial load in the right wall (A) and moment at the base of the walls (B) for a signal of $0.55 \mathrm{~g}$.

The damage theory implemented in the model used for concrete allowed the study of the variation of damage suffered in different points of the section. As an example, the damage suffered by the left wall calculated at one of the four corners of the section, for the $0.55 \mathrm{~g}$ excitation, is plotted in Figure 17. The effects of tension and compression are considered separately. From the graphs it can be observed that the effects of tension are maximum at the base of the wall, and decrease in the upper stories. On the con-

Damage due to compression
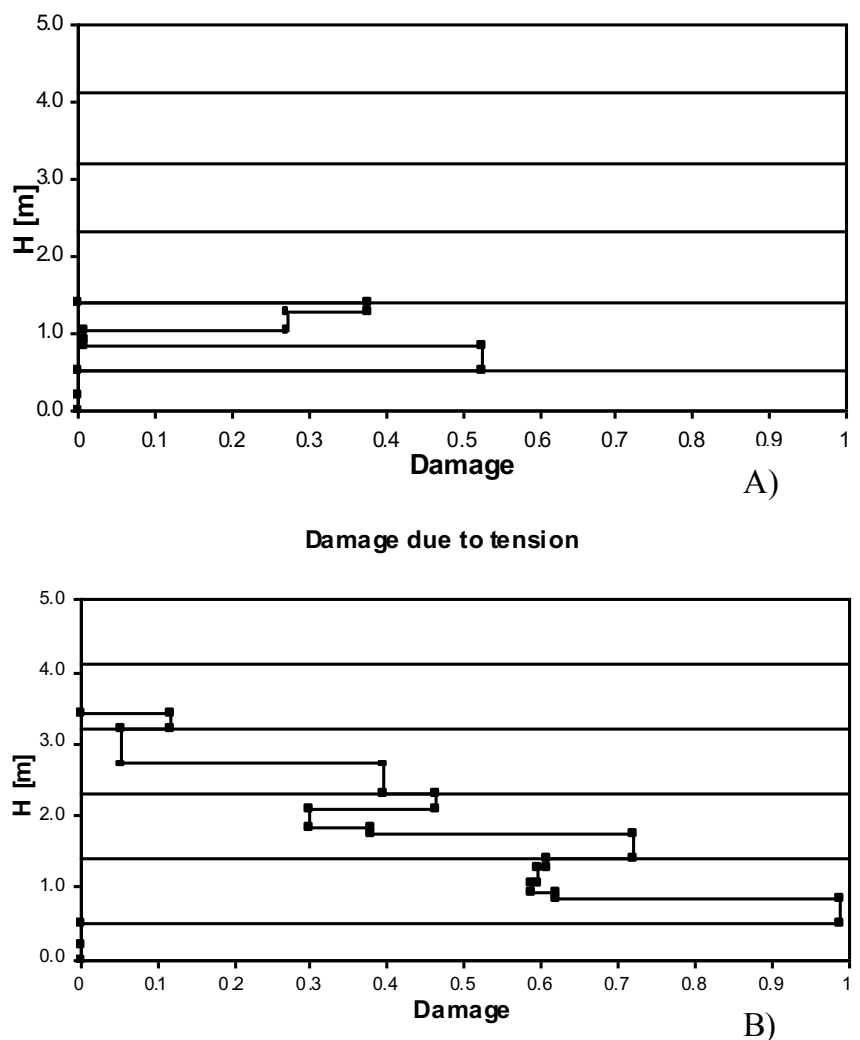

trary, compression causes damage only in the first story, ed in particular close to the basement and to the connection with the slab of the first story, where the maximum damage occurs, as it was observed during the tests.

Figure 17. Damage evolution in one of the corners of the left wall: A) contribution due to compression; B) contribution caused by tension.

These results have proved the ability of an explicit model and scheme of resolution to simulate the response of a mock-up submitted to a series of earthquake excitation. This was a first step to validate the modelling, however the main use will be, in the future, for dynamic problems at high velocity such as impacts.

Rock falls are common in mountain regions and protection systems have to be placed particularly on roads. Figure 18 gives an example of calculations 
performed with the PRM model used with an explicit scheme in order to analyse the efficiency of a reinforced concrete slab set up to protect a road and to play the role of a deflector for boulders. Experiments have been performed and the simulation is able to describe the main phenomena as tensile damage presented in Figure 18. This work is in progress.

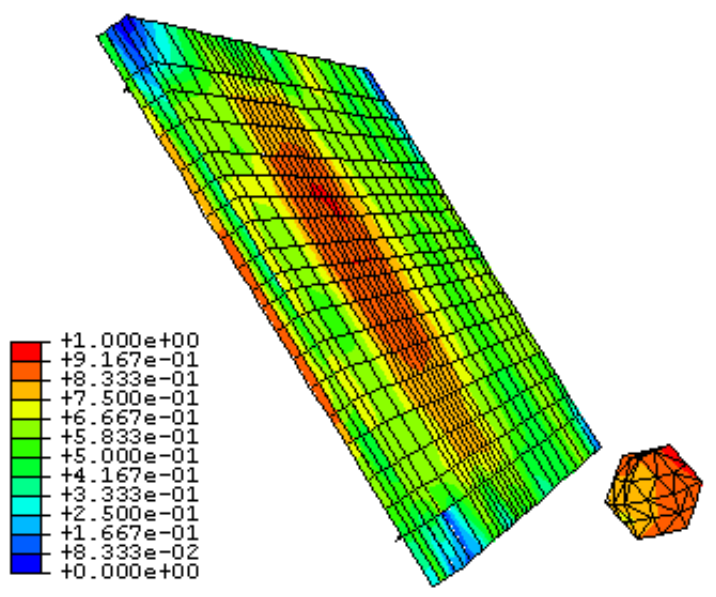

Figure 18. Inclined reinforced concrete slab submitted to rock fall - Simulation of damage induced $\left(D_{t}\right.$ into the slab and into the boulder with the PRM explicit model) by an impact of a boulder $(450 \mathrm{~kg}$ from $30 \mathrm{~m})$ in the center of the slab.

\section{CONCLUSIONS}

The dynamic behaviour of a five-storeys shear wall building has been simulated in this study by using analytical models characterised by different levels of discretisation. The efficacy of a 3D finite element thin shell model, a beam and a fibre model have been verified by using the results of a shaking table test campaign performed within the CAMUS 2000 research programme.

As demonstrated by the results reported in the paper, not only the refined model but also the two simplified models were able to reproduce with good approximation the main features of the global response of the structure. This confirms that the level of discretisation and the type of numerical elements adopted in both simplified models are sufficient to describe the dynamic behaviour of wall structures. This is so also thanks to the stress-strain laws chosen to model the behaviour of steel and concrete. The accuracy of the results obtained for local indicators, e.g. elongation of rebars, damage index, etc, is reduced due to the hypothesis adopted in the modelling phase. The computation of damage in concrete can be cited as an example. The damage pattern evaluated with the 3D finite element thin shell model corresponds perfectly to that observed in the reality. On the contrary, by using the beam model only the general trend was represented.

The limited accuracy characterising the results obtained with simplified models of the same type of those considered in this paper is balanced by their reduced computational cost. This aspect assumes a fundamental importance when parametric studies or vulnerability analyses have to be performed (Negro \& Colombo 1998).

The results of the experimental campaign indicate that the out-of-plane excitation can significantly increase the flexural demand of reinforced concrete walls with limited reinforcement, mainly because of the increase in the variation of the axial force, which is of the same order of magnitude than that due to permanent loads. Independently from the level of discretisation, the non-linear models considered in this study are able to realistically estimate the range of variation of the axial force. In addition to the ability in modelling the non-linear behaviour, the capacity to describe the variation of the axial load underlines the importance of a more close interaction between non-linear analysis and design.

Two ways of research are currently under investigation:

1- The ability of existing macro models with standard computer codes to model the global parameters of the response of a structure. The multiplevertical-line-element model - MVLEM was chosen as the reference model. This study will be extended to the results of dynamic tests that will be performed at the shaking table facility of the LNEC. The specimen differs from the one considered in the study reported in this paper from the fact that the steel bracing system used to provide stiffness in the transversal direction is replaced by a more realistic reinforced concrete wall with openings.

2- The close agreement between the experimental and the analytical results obtained with the beam model verified the efficacy of explicit methods -the integration algorithms and more specifically the PRM model used to describe the behaviour of concrete- to simulate the response of structures subjected to dynamic loads. This validation allowed for the use of the same explicit model for dynamic problems of different nature. As an example, it is now used to study the effects of impact of blocks on reinforced concrete slabs.

\section{REFERENCES}

Armstrong, P.J \& Frederick, C.O. 1966. A Mathematical Representation of the Multiaxial Bauschinger Effect. G.E.G.B. Report $R D / B / N 731$.

ASCE 1982. State-of-the-art report on finite element analysis of reinforced concrete. ASCE special publication, New York, N.Y.

Bisch, P. \& Coin, A. 1998. The CAMUS research. Proceedings of the $11^{\text {th }}$ European Conference on Earthquake Engineering, Paris, CD-ROM.

Bisch, P. \& Coin, A. 2002. The "CAMUS 2000" research. Proceedings of the $12^{\text {th }}$ European Conference on Earthquake Engineering, London, CD-ROM. 
Caughey T., 1960. Classical normal modes in damped linear systems. Journal of Applied Mechanics, 27, pp. 269-271.

Combescure, D., Queval J.C., Chaudat, T. and Sollogoub P., 2002. Seismic Behaviour of Non Symmetric R/C Bearing Walls Specimen with Torsion. Experimental Results and Non Linear Numerical Modelling. Proceedings of the $12^{\text {th }}$ European Conference on Earthquake Engineering, London, CD-ROM.

Fardis, M.N. 2000. Eurocode 8 - Present state, pre-normative and co-normative research needs (including design seismic action). Proceedings of the Workshop: Mitigation of Seismic Risk Support to Recently Affected European Countries, European Commission-JRC, Belgirate (VB), Italy.

Fleury, F. 1996. Prediction of the behaviour of reinforced concrete structures subjected to seismic loading: proposal for a global model for beam column joints integrating the behaviour of steel/concrete bond. Ph.D. Thesis, Blaise Pascal - Clermont II University, France.

Fouré, B. 2001. CAMUS 2000 Project - Control of execution of the specimens. Report No. R112-9-348, CEBTP, (in French).

Ile, N. 2000. Behaviour of reinforced concrete walls under seismic loading: contribution made by experiment and modelling to design. Ph.D. Thesis, National Institute for Applied Sciences, Lyon, France.

Ile, N. \& Reynouard, J. M. 2000. Non-linear analysis of reinforced concrete shear wall under earthquake loading. Journal of Earthquake Engineering, Vol 4, No 2, 183-213.

La Borderie, Ch. 1991. Phénomènes unilatéraux dans un matériau endommageable : modélisation et application à l'analyse de structures en béton. Ph. D. thesis: Univ. Paris VI.

Mazars, J., 1986. A Description of Micro- and Macroscale Damage of Concrete Structures, Engineering Fracture Mechanics, V.25,No. 5/6.

Mazars, J. 1998. French advanced research on structural walls: An overview on recent seismic programs. Proceedings of the $11^{\text {th }}$ European Conference on Earthquake Engineering, Invited Lectures, Paris, CD-ROM.

Menegoto, M. \& Pinto, P. 1973. Method of analysis of cyclically loaded reinforced concrete plane frames including changes in geometry and non-elastic behaviour of elements under combined normal force and bending. IABSE Symposium on resistance and ultimate deformability of structures acted on by well-defined repeated loads, Final report, Lisbon.

Merabet, O. \& Reynouard, J.M. 1999. Formulation d'un modèle elasto-plastique fissurable pour le béton sous chargement cyclique. Contract Study EDF/DER, Final Report, No.1/943/002, URGC-Structures, National Institute for Applied Sciences, Lyon, France.

Millard, A. 1993. CASTEM 2000, Manuel d'utilisation. Report CEA-LAMBS No. 93/007, Saclay, France.

Negro P., \& Colombo A. 1998. How Reliable are Global Computer Models? Correlation with Large-Scale Tests. Earthquake Spectra, Vol. 14, No. 3, pp. 441-467.

Rouquand, A., \& Pontiroli, C. 1995. Some Considerations on Implicit Damage Models Including Crack Closure Effects and Anisotropic Behaviour. Proceedings FRAMCOS-2, Ed. F.H. Wittmann, AEDIFICATIO Publisher, Freiburg.

Rouquand, A., Mazars, J. 2001, modèle incluant endommagement et dissipation hysteretique couplée, internal report CEG -DGA Gramat, France

Vulcano, A., Bertero, V.V. and Colotti, V 1988. Analytical Modeling of R/C structural walls. Proceedings of the $9^{\text {th }}$ World Conference on Earthquake Engineering, Vol.VI, Tokyo-Kyopto, Japan. 